\title{
Chapter 10 \\ Oral Care that Supports Healthy Lives as a Case Study of the Kumamoto Earthquake
}

\section{Michikazu Hiramatsu and Hideto Ohta}

\begin{abstract}
Immediately after the Great Hanshin-Awaji Earthquake in 1995 and the Great East Japan Earthquake in 2011, pneumonia outbreak among the elderly increased the rate of fatalities. What caused this? To use lessons learned during the large-scale disaster, specialists concerned with the field of dentistry began to take action using new perspectives. Consequently, they noticed the importance of giving care to the entire oral cavity as well as the teeth. Based on reports from a dentist and a dental hygienist who tackled the oral care of the Kumamoto Earthquake victims in 2016, their methods of effective health care following a disaster is presented in this paper. We also propose a preventative medical activity that can be conducted sustainably for anyone, not just medical personnel.
\end{abstract}

Keywords Disaster-related deaths · Oral care · Pneumonia outbreak · Preventive health care

\section{The Rapid Increase of Pneumonia After the Disaster}

In the last quarter-century, Japan experienced four large-scale earthquakes: the Great Hanshin-Awaji Earthquake of 1995 (M7.3), the Niigata-Chuetsu Earthquake of 2004 (M6.8), the Great East Japan Earthquake of 2011 (M9.0), and the Kumamoto Earthquake of 2016 (M6.5, M7.3). In every case, many fell victim to house and building collapses, landslides, and tsunamis, but many earthquake-related deaths occurred in the evacuation shelter afterward.

Pneumonia was the top cause of death (Takakura et al. 1997; Suzuki et al. 2011; Daito et al. 2013; Shibata et al. 2016). Although the proportion of death from

\footnotetext{
M. Hiramatsu $(\bowtie)$

The Institute of Decision Science for a Sustainable Society, Kyushu University, Fukuoka, Japan

H. Ohta

Fukuoka Dental Association, Dazaifu, Japan

e-mail: droota@grace.ocn.ne.jp 
pneumonia is usually about $10 \%$, in the disaster-related death toll after the Great Hanshin-Awaji Earthquake, it was reported as 24\% (Adachi 2015).

Based on the report, the medical stakeholders began to acknowledge that "pneumonia of the elderly increases after a large earthquake occurs" or "oral care to the elderly is necessary to prevent pneumonia." Indeed, in the Niigata-Chuetsu Earthquake in 2004, the oral care team was organized for the elderly by dental personnel, who previously concentrated their attention on the identification of the dead and emergency dental care as their main disaster support. The Niigata-Chuetsu Earthquake was the first event where oral care was used in victim relief (Tanaka 2009; Nakakuki et al. 2012).

\section{Pneumonia Outbreak After the Great East Japan Earthquake}

The Great East Japan Earthquake of March 11, 2011, caused a major tsunami that struck the coast of the Tohoku region and was a catastrophe that caused death and missing people beyond the extent of the Great Hanshin-Awaji Earthquake. In this chaotic situation of an unprecedented catastrophe, the repeated nightmare of a sudden increase in fatalities due to pneumonia was reported by detailed data tracking by physicians who assisted in the disaster area.

Kesennuma, Miyagi prefecture is a city with a population of 70,000 located on the east coast of Tohoku that was affected by the Great East Japan Earthquake. After the disaster, pneumonia patients were carried incessantly into Kesennuma City Hospital, and the hospital filled with patients immediately in a few days.

Daito et al. (2013) conducted a detailed analysis of the rapid increase in pneumonia based on the medical records and X-ray photographs of pneumonia patients aged 18 and more before and after the earthquake at three city hospitals. The research revealed that 225 people (The frequency per week was 5.7 times before the disaster) were hospitalized with pneumonia within three and a half months afterward. One hundred and eighty-four (88\%) were elderly aged over 65 years. Forty-nine people (24\%; frequency was 8.9 times before the disaster) had lost their lives. Daito et al. (2013) eventually ascertained that typical pneumonia seen in the elderly increased more than in normal times, though it was also believed that pneumonia would spread if oil dust floating in the disaster area were inhaled.

It should be stressed that the pneumonia mortality rate $(2.1 \%)$ at the elderly nursing home was far higher than the pneumonia mortality rate $(0.1 \%$ or less $)$ at the evacuation center. In the elderly nursing home in the city-where 125 patients were kept in overwhelming numbers, and six people were being accommodated per quadruple-sized rooms-five people developed pneumonia in the first 20 days, and all of whom died.

Detailed data on the rapid increase of pneumonia after the disaster by Daito et al. (2013) effectively shows how important it is to protect elderly people who need 
long-term care from pneumonia in an adverse environment where their lifeline is disrupted during a severely cold season. In Daito et al.'s survey, however, it was not concluded what the main factor among multiple conditions such as age and stress involved with pneumonia was.

\section{The Importance of Oral Care}

How can I protect the elderly from pneumonia? The answer was unexpectedly given by another special elderly nursing home-Keichoen in Kesennuma city. After the earthquake, among 100 elderly people, no one developed pneumonia or was hospitalized who had evacuated to this nursing home (https://www.nhk.or.jp/ashita/ english/stories/tmrw3-pneu.html).

This miracle at the facility, given the generally high risk of developing pneumonia, became possible through oral hygiene management by dental doctors who came from local and other prefectures. Considering the water shortages, the inside of oral cavities were cleaned using a forefinger wrapped in wet, nonwoven fabric instead of a toothbrush, and the salivary glands were massaged to promote saliva secretion. Yoneyama et al. (1999) also reported that 2 years of incidences of pneumonia at a special nursing home (where residents were visited by a dentist or a dental hygienist conducting specialized oral cleaning) was reduced by about $40 \%$ compared with those without such cleaning. Such oral hygiene management might suppress bacterial growth in the oral cavity.

Doctor Daito, who learned the effectiveness of this oral hygiene management, mentioned later that "I could never imagine at that time that the dentist had predicted the pneumonia outbreak and was involved in aggressive oral care to prevent it." As his view explains, it was challenging to predict pneumonia at the time of disaster within normal specialized frameworks and prevent its rapid surge.

As mentioned, the experience and wisdom of disaster-stricken medical care providers from the Great Hanshin-Awaji Earthquake to the Great East Japan Earthquake increased awareness for the importance of collaborative medicine between medical and dental fields beyond their specialties. Gradually, preparing support systems for oral care for victims during a disaster accelerated (Nakakuki et al. 2012, 2013). Ohta, an author of this present review, is also a dental care worker who learned and began providing oral care support for victims after their medical volunteer activities at a disaster site. 


\section{Oral Care Activities by Dentists and Dental Hygienists for Reducing Pneumonia Outbreak After the Kumamoto Earthquake}

Like Daito, Ohta et al. (2019) learned the scientific basis for the importance of professional oral cleaning after he experienced on-site dental support in Minamisanriku, Miyagi Prefecture, 2 months after the Great East Japan Earthquake. Through that experience, Ohta realized that, if more dental personnel could conduct oral care activities targeting patients with a high risk of pneumonia within two weeks after an earthquake, more people would be saved.

The opportunity to test the idea came on April 16, 2016, when a substantial earthquake hit Kumamoto, approximately $100 \mathrm{~km}$ away from Ohta's residence. After the earthquake, Ohta and other dental workers were requested to join local Kumamoto dentist associations in the field, and dental health support activities were conducted.

In the severely damaged Minamiaso village (approximately 11,600 population), the Disaster Medical Assistance Team (DMAT), Japan Medical Association Team (JMAT), public health nurses, and pharmacists formed a team under the direction of the Aso Disaster Recovery Organization (ADRO) immediately after the main shock to conduct emergency medical activities. The local Kumamoto Prefecture dentist members also participated in this. Ohta's dental team dispatched from outside Kumamoto Prefecture entered the village on April 23, seven days after the earthquake. The dental team mainly developed cross-organizational support activities through multidisciplinary professional collaboration with the Japan Rehabilitation Assistance Team (JRAT) and the Japan Dietetic Association-Disaster Assistance Team (JDA-DAT).

Ohta's dental support team used the national standardized assessment form (http://jsdphd.umin.jp/shiryo.html) for the first time in the disaster area. Consequently, it is possible to clarify the necessity of dental treatment and oral care at the individual and group level, and to quickly collect information on persons who require special consideration in shelters and nursing homes that were blind spots in the Great East Japan Earthquake. The dental team developed a support plan for the entire region based on the collected information and shared it with non-dental occupations such as doctors, nurses, nutritionists, physical therapists, social workers, and logistic officers at the emergency management headquarters meeting. The Disaster Feeding Support Team (DFST), which is composed of trans-disciplinary professional members, provided meals to prevent dysphagia in elderly people requiring special consideration (Maeda et al. 2017; Kato et al. 2019).

In Minamiaso village, Ohta's emergency team received 46 dental and 252 oral care treatments (Ohta et al. 2019). Sixty-nine swallowing evaluations and 12 swallowing rehabilitations were performed within the one-month dispatch period from April 23 to May 22, 2016. During this period, there was one pneumonia patient who required hospitalization, and no disaster-related deaths due to pneumonia were identified until a half year after the disaster. 
As already mentioned, the pneumonia incidence in the Great Hanshin-Awaji Earthquake was as high as $24 \%$ of the deaths related to the earthquake (Adachi 2015). Although the incidence of pneumonia due to the Kumamoto earthquake is not yet clear, A Nishinippon Shimbun newspaper published on May 22, 2016, reported that the number of pneumonia patients during the 16 days after the Kumamoto Earthquake increased compared to the same period of the previous year in the two disaster base medical hospitals in Kumamoto city (population, 740,000) (https://www.nishinippon.co.jp/nnp/medical/article/247976/). Based on these facts, it can thus be said that the medical and health activity through collaboration between dentistry, dental hygiene, and various professionals in Minamiaso village was a successful example of reducing disaster-related deaths.

Recently, the importance of medical-dental collaboration through oral care is widely recognized in the field of medical welfare. In medical treatment at the time of a disaster, however, since full-time doctors are often pursued to manage patients urgently transported under the relatively poor working conditions, there may be cases where normal oral care cannot be sufficiently performed. There are various types of facilities for receiving victims, such as base hospitals, clinics, welfare facilities, and temporary shelters, and the handling scale and content differ by the facility.

To functionally work preventative oral care for elderly pneumonia sufferers, even during disasters, it is necessary to predict the condition and number of patients that can be accepted during a disaster. Eventually, each facility will be requested to establish a business continuity plan (BCP) including how to accept medical supporters from outside the organization, to check it daily, and improve it after the disaster.

\section{Mouth Breathing, Its Causes, and Adverse Effects: What People Can Do for Sustainable Health}

Life after disasters tends to be worse than is normal, and it is important for health maintenance that medical supporters and evacuees prevent a decline in autoimmunity. One example is the "A-I-U-Be" exercise proposed by Imai, a physician (https:// mirai-iryou.com/aiube/aiube-english/).

People who take modern diets of soft foods that do not require much chewing power tend to weaken the muscle strength around the mouth and that of the tongue, and will eventually be in a state of "mouth breathing," where the mouth is always open. A person in the mouth breathing state takes air directly into the mouth more easily. Thus, saliva secretion is suppressed, and their oral cavities become drier. This reduces autoimmunity and increases the chances of suffering from diseases caused by bacteria and viruses.

The A-I-U-Be exercise prevents mouth breathing and raises autoimmunity by returning the tongue to a normal position and naturally closing the mouth. This 
exercise has often been adopted in schools due to the simplicity of doing it anytime, anywhere without cost. Although not statistically estimated, clear suppression of winter flu in school children was reported from some elementary school that adopted the exercise.

Evacuees in disaster areas can significantly reduce the risk of respiratory diseases such as flu and pneumonia by performing self-cleaning in the oral cavity and such simple exercises. Consequently, it will be possible to prevent disaster-related deaths. At Minamiaso village, Ohta's dental team urged evacuees to use the A-I-U-Be exercise while handing out cards (https://mirai-iryou.com/aiube/contact-aiube/\#i-3) explaining the method and effect of this exercise. Therefore, educating residents likely to become disaster victims on the knowledge and skills to maintain their health, even in a poor environment, is also indispensable for saving lives in the disaster areas. Moreover, the accumulation of scientific evidence on the effect of these health activities in disaster areas is a challenge for the future.

Acknowledgments This work was supported by a grant JPMJRX16F1 from the Research Institute of Science and Technology for the Society (RISTEX) of Japan Science and Technology Agency (JST) as part of the Future Earth programs.

\section{References}

Adachi R (2015) Importance of oral health in large-scale disasters - to halt an increase in disasterrelated deaths. J Kanagawa Odontol Soc 50:18-21

Daito H, Suzuki M, Shiihara J, Kilgore PE, Ohtomo H, Morimoto K, Ishida M, Kamigaki T, Oshitani H, Hashizume M, Endo W, Hagiwara K, Ariyoshi K, Okinaga S (2013) Impact of the Tohoku earthquake and tsunami on pneumonia hospitalisations and mortality among adults in northern Miyagi, Japan: a multicentre observational study. Thorax 68:544-550

Kato T, Morita H, Tsuzuki T, Yamaguchi M, Ohta H, Tanoue D, Nakakuki K (2019) Emerging role of dental professionals with medical staff collaboration in disaster relief following the 2016 Kumamoto earthquakes: implications for the expansion of the scope of dental practice. Int Dent J 69:79-83

Maeda K, Shamoto H, Furuya S (2017) Feeding support team for frail, disabled, or elderly people during the early phase of a disaster. Tohoku J Exp Med 242:259-261

Nakakuki K, Tohara H, Kojo A (2012) Research for arrangement of dysphagia in a dental health care management system during large-scale disasters. Jpn J Dysphagia Rehab 16:57-63

Nakakuki K, Arikawa K, Taguchi C, Ogura M, Nasu I, Teraoka K (2013) Preparation for disaster dental aid and health system in prefectures. Health Sci Health Care 13:67-75

Ohta H, Nakakuki K, Tanoue D, Katayama K, Niibu I, Kumai T, Mimori Y, Tamura N, Ganaha S, Koshikawa Y, Ushijima T, Urata K (2019) Multidisciplinary "eating" support by maintaining oral function for vulnerable people in Minamiaso area after the 2016 Kumamoto Earthquake. J Jpn Disaster Food Soc 6:69-76

Shibata Y, Ojima T, Tomata Y, Okada E, Nakamura M, Kawado M, Hashimoto S (2016) Characteristics of pneumonia deaths after an earthquake and tsunami: an ecological study of 5.7 million participants in 131 municipalities, Japan. BMJ Open 6:e009190

Suzuki M, Uwano C, Ohrui T, Ebihara T, Yamasaki M, Asamura T, Tomita N, Kosaka Y, Furukawa K, Arai H (2011) Shelter-acquired pneumonia after a catastrophic earthquake in Japan. J Am Geriatr Soc 59:1968-1970 
Takakura R, Himeno S, Kanayama Y, Sonoda T, Kiriyama K, Furubayashi T, Yabu M, Yoshida S, Nagasawa Y, Inoue S, Iwao N (1997) Follow-up after the Hanshin-Awaji Earthquake: diverse influences on pneumonia, bronchial asthma, peptic ulcer and diabetes mellitus. Intern Med 36:87-91

Tanaka A (2009) Dental health support activities for struck senior citizen in the large-scale disaster. J Jpn Dent Assoc 62:392-404

Yoneyama T, Yoshida M, Matsui T, Sasaki H, Oral Care Working Group (1999) Oral care and pneumonia. Lancet 354:515

Open Access This chapter is licensed under the terms of the Creative Commons Attribution 4.0 International License (http://creativecommons.org/licenses/by/4.0/), which permits use, sharing, adaptation, distribution and reproduction in any medium or format, as long as you give appropriate credit to the original author(s) and the source, provide a link to the Creative Commons license and indicate if changes were made.

The images or other third party material in this chapter are included in the chapter's Creative Commons license, unless indicated otherwise in a credit line to the material. If material is not included in the chapter's Creative Commons license and your intended use is not permitted by statutory regulation or exceeds the permitted use, you will need to obtain permission directly from the copyright holder. 